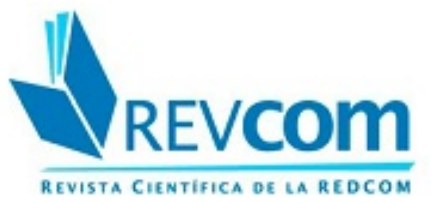

REVCOM. Revista científica de la red de carreras de Comunicación Social

ISSN: 2451-7836

redcom.revcom@gmail.com

Universidad Nacional de La Plata

Argentina

\title{
Pensar contra el género
}

Palermo, Zulma

Pensar contra el género

REVCOM. Revista científica de la red de carreras de Comunicación Social, núm. 9, 2019

Universidad Nacional de La Plata, Argentina

DOI: https://doi.org/10.24215/24517836e014 


\section{Pensar contra el género}

\section{ReSUMEN:}

Se propone reflexionar acerca de la cuestión de género desde una perspectiva decolonial, buscando comprender la dimensión del poder del patriarcado en el funcionamiento de nuestras sociedades atravesadas por la colonialidad. A partir de algunas proposiciones precedentes sobre la relación género-raza, acá se pone el acento en la colonialidad del lenguaje, actualizando los posicionamientos de los últimos feminismos enriquecidos por los aportes de estudioses no occidentales.

Palabras ClaVe: patriarcado, colonialidad del género, colonialidad del lenguaje, feminismos otros.

\section{Resumo:}

Proponho nestas páginas refletir sobre a questão de gênero com uma perspectiva decolonial, buscando compreender a dimensão do poder do patriarcado no funcionamento de nossas sociedades atravessadas pela colonialidad. Partindo de algumas proposições precedentes sobre a relação gênero-raça, aquí coloca-se o acento na colonialdiade da linguagem, atualizando os posicionamentos dos últimos feminismos enriquecidos pelas contribuições de estudioses no ocidentais.

PalaVras-ChaVe: patriarcado, colonialidade de gênero, colonialidade da linguagem, feminismos outros.

... cómo pensar no sólo contra el género, sino [...] más allá de su matriz ideológica heterosexual y jerárquica, y con prácticas que lo desestabilicen, socaven, transgredan e interrumpan; con prácticas que creen, construyan y permitan la integración, movilidad y el tránsito y que provoquen las energías espirituales y creativas de lo andrógino como un-modo-muy-otro del género.

Catherine Walsh (2016)

En estas páginas me interesa reflexionar a partir del desafío del epígrafe, acerca de la cuestión de género desde una perspectiva decolonial, buscando comprender la dimensión del poder del patriarcado en el funcionamiento de nuestras sociedades atravesadas por la colonialidad. En esa dirección es relevante poner en evidencia que las acciones concretadas por el ya más que centenario movimiento feminista ha marcado fuertemente en los últimos años la perspectiva, para reconfigurar el sentido de la diferencia sostenido por los discursos de fundación de la opción decolonial ${ }^{1}$, acentuando la relación estrecha entre raza y género tramada en la estructura patriarcal propia de las sociedades coloniales y revisando críticamente tanto la mirada decolonial como la de género vigente.

La ruptura histórica que produjo la irrupción de la crítica de género en los desarrollos del pensamiento alternativo fue decisiva, porque es precisamente esa presencia la que hizo posible la puesta en evidencia del "paradigma patriarcal" en tanto "modelo de invisibilización" como sostiene María Luisa Femenías (2004). Los efectos de esa crítica fueron muchos y abarcan distintos niveles de funcionamiento; sobre todo produjo una fuerte revulsión teórica haciendo evidente la relación necesaria entre las prácticas teóricas y los movimientos sociales, violentando de manera directa los límites de la concepción de género construida por la matriz patriarcal de poder.

Lo señalaba así en una ya lejana aproximación a la problemática que acá interesa, afirmando en ese momento que en la formación de las categorías de raza y de género funciona una forma de poder ejercido 
sobre las diferencias coloniales que las definen por relación con el otro étnica o genéricamente marcados. De allí que la formación de la(s) representación(es) de género tanto como la(s) de etnicidad respondan a una construcción de la diferencia entendida como un patrón de relaciones de poder históricamente necesarias y permanentes a partir de un estatuto biológico y cultural fuertemente consolidado, según las que el "otro" es denegado. Algunos rasgos constitutivos de esa matriz se definen como "núcleos duros" de la cultura, con permanencia en las construcciones más sobresalientes del imaginario moderno y con vigencia hasta nuestros días: la mujer, del mismo modo que el varón negro o indígena, queda definida por su ingenuidad, su incapacidad para el razonamiento y las actividades superiores de la abstracción y la producción de conocimiento; ambes tienden además, con particular similitud, a la lascivia (o la provocan) y son percibides como objetos de uso (productores de plusvalía económica los unos, de reproducción de la especie las otras), incapaces de construir autónomamente sus subjetividades y de ejercer roles públicos de autoridad y de poder (Palermo, 2009).

La estructura patriarcal de nuestras sociedades, caracterizada por las relaciones de poder que Aníbal Quijano señalara y que sustenta los haceres, decires y pensares de la opción decolonial ${ }^{2}$, sostienen todas las diferencias antes mencionadas y ponen en funcionamiento todos los controles ejercidos sobre ellas. Los tres elementos que las determinan: dominación, explotación y conflicto, actúan complementariamente en la formación de las subjetividades y, sin duda, en el tipo de relaciones que se establecen hacia dentro de las que son propias de la heterogeneidad que incluye la idea de género. De allí que, como piensa Catherine Walsh,

$\mathrm{Si}[\ldots]$ las categorías de género y patriarcado son parte del arsenal de las herramientas del amo -de la razón imperial-, con la que es imposible destruir su morada o casa, ¿cuánto valor tiene el pensar con y desde posturas, perspectivas y experiencias que transgreden, interrumpen y rompen con los universalismos, los dualismos y las pretensiones hegemónicas que esas categorías anuncian y construyen? [...] ¿de qué manera esos procesos podrían contribuir no sólo a la descolonización del género sino también $[. .$.$] al reconocimiento, pasado y presente, de un modo-muy-otro? (2016:179)$

La ideología patriarcal del espacio-tiempo doméstico tiende, de hecho, a influir sobre la subordinación de la mujer en el mercado de trabajo, siendo adoptada tanto por el capital en el espacio-tiempo de la producción, como por el Estado en el espacio-tiempo de la ciudadanía que la institucionaliza, en el campo del derecho penal, del derecho de familia y de la seguridad social

(1998: 396-397).

Los avances concretados hasta acá en orden a reflexionar sobre el proceso que puede dar lugar a ese "modomuy-otro" ${ }^{3}$, invitan a volver a mirar para comprender lo que acontece en nuestros días en los cotidianos y extendidos actos de "violencia de género" (y más allá), su difusión mediática y su efecto jurídico y normativo ${ }^{4}$. Estos actos, evidentes en las prácticas más domésticas de la vida cotidiana, se sostienen, por un lado, en la estructura de la organización social occidental según la que se define una clara división de la fuerza del trabajo como estrategia para poner en práctica una diferencialidad remunerativa, como ya señalara, llegando a la exclusión del espacio laboral de quienes se definen por fuera de la norma heterosexual. Tal cuestión se releva, a manera de caso y con sobrada evidencia, en la invisibilización social del espacio de trabajo doméstico ya sea que se realice por la mujer-ama-de-casa o por otres contratades para tal finalidad, ambes vinculades por el rasgo común de la servidumbre como lo explicita B. de Souza Santos

\section{EL IMPERIO DE LA LENGUA}

Más allá de esos espacios, la institución que normaliza el uso de la lengua -dominio por antonomasia de la colonialidad $^{5}$ - ejerce una función coercitiva, tal vez no tanto por lo que no deja decir como por lo que obliga a decir, Así, en nuestra lengua, el uso del género masculino fue y sigue siendo impositivo, explícitamente marcado, en posición dominante sobre el femenino: la lengua normaliza la diferencia masculino / femenino, 
relación desigual en la que el término "femenino" queda sometido a la autoridad del masculino, en clarísima asunción de la diferencia colonial que antes señalara, en relación de superioridad / inferioridad.

Pienso, entonces, en las estrategias que, en ese orden, se han venido haciendo-diciendo en el espacio de los movimientos sociales como activadores de la "opinión pública" ${ }^{6}$. Cada vez más claramente se hace visible que los movimientos que se iniciaran como "feministas" y así actuaran hasta las últimas décadas del s XX, han sido el espacio de expresión y visibilización de otras diferencias de sexualidad tanto o más marcadas negativamente que las de género/raza, aunque siempre entramadas con éstas: gays, homosexuales, lesbianas, travestis, queers, encontraron allí inicialmente un lugar de complementariedad a la vez que de diferenciación. Se trata, ahora, de un "feminismo" confrontado con el de su constitución tradicional que activa, a través de sus luchas cada vez más eficaces, prácticas de resistencia callejera no sólo voceadas, sino textualizadas en graffitis, pasacalles, investigaciones académicas difundidas en artículos especializados, etc. Es en este tipo de comunicación lingüística en la que se habla de-por-sobre-desde la situación "de género" buscando construir $s u$ diferencia al interior de un sujeto social complejo y contradictorio, donde surge la necesidad de encontrar usos del lenguaje que borren la diferencia de género en lucha con la gramática normativa, en la convicción de que la aparición de nuevos sujetos políticos reclaman formas de comprensión e interrelación que sustituyan a las hegemónicas. ${ }^{7}$

La circulación oral -y también escrita- de esos movimientos ha venido haciendo uso de una forma que responde al mandato de la norma gramatical: "todos/todas", particularmente en las maneras más formales de la comunicación, siempre dentro de la dualidad que supone la idea binaria de género. La cuestión es que esta marca no contempla la diversalidad sexual que sabemos integra el género por lo que, buscando subsanarlo, se pusieron en circulación grafemas que buscan resolver el binarismo (uso de X o de @), usos que conllevan dificultades de otro tipo ya que, como es evidente, sólo funcionan en la lengua escrita, ya que no pueden ser pronunciados oralmente. Otro horizonte es el que ofrece el uso de $e$ que no produce dificultades en ninguna de las dos formas de circulación discursiva y que, si bien podría pensarse es en exceso generalizadora, viene a dar una respuesta consistente a la imperiosa necesidad de nombrar a todes borrando las distinciones jerarquizantes.

Ante la rápida expansión de este uso, surgió la sanción normativa en manos de la poderosa RAE (actualizando la convicción nebrijeana de que la lengua es la compañera del Impero), que impugna el uso y obliga a seguir la norma gramatical en su variación genérica binaria en la "norma culta". Ratifica así la distribución jerárquica de roles sociales denegando e ignorando lo que -en el caso argentino- ya se encuentra, aunque todavía de manera parcial, jurídicamente establecido. Con este mandato refrenda la RAE una prescripción gramatical previa definida por su normativa, que sanciona como incorrecto el llamado leismo ${ }^{8}$ usado en algunas regiones de la extensa abarcación de la lengua castellana desde la Edad Media (Andalucía y América Hispana). El texto académico explicita al respecto, en su Diccionario panhispánico de dudas, entre otras cuestiones de orden etimológico que

2. Debido a su extensión entre hablantes cultos y escritores de prestigio, se admite el uso de le en lugar de lo en función de complemento directo cuando el referente es una persona de sexo masculino [...] El leísmo no se admite de ningún modo en la norma culta cuando el referente es inanimado [...] Y tampoco se admite, en general, cuando el referente es una mujer [...], aunque existen algunos casos en que el leísmo femenino de persona no se considera incorrecto. (RAE, 2005. El destacado es mío)

4.f ... No obstante, también se documentan ejemplos en los que no se da este tipo de leísmo, especialmente en el Perú y los países del Cono Sur [...]. Aunque el «leísmo de cortesía» no está tan generalizado cuando el interlocutor es femenino, debe considerarse aceptable, especialmente en fórmulas fijas de saludo o despedida... (Íbid)

Queda acá claramente enunciado que existe una estrecha relación entre género gramatical y biológico, no sólo acotado a la prescripción heterosexual, sino también a la diferencia que señala la posición inferiorizada de la mujer, que ocupa el mismo lugar que las cosas (lo inanimado). 
Por otro lado, resulta significativo que, por el contacto del castellano con lenguas nativas de nuestro continente, sea admisible su uso por la relación forzosa entre ambas, dando cuenta de la inexistencia de la diferencia entre masculino / femenino en esas culturas, siempre destacando el orden jerárquico entre las lenguas y su uso, ahora en las relaciones interculturales:

5. En algunas zonas de España y América se producen casos de leísmo debidos al contacto del español con otras lenguas que se caracterizan por no contar con distinción de género y por marcar el número y el caso de forma muy diferente al español. Estas lenguas son el quechua, el aimara, el guaraní y el vasco. Las confusiones tienen su origen en la difcultad que plantea el uso correcto del español a los hablantes que normalmente se expresan en esas otras lenguas. En muchos casos estos usos no son exclusivos de los hablantes bilingües de escasa formación, sino que, en general, han pasado a formar parte del habla corriente de las respectivas zonas, pero no se consideran admisibles desde el punto de vista de la norma culta estándar (salvo el leísmo de persona con referente masculino singular). (Íbid)

Se agrega acá a las aserciones que acentúan la diferencia colonial de género, una vez más, la de etnicidad ya que se atribuye la "dificultad" de las culturas precoloniales para el uso correcto de masculino / femenino en español, a que en sus lenguas (el caso andaluz es atribuible a la incidencia de la cultura árabe en la Península) no tienen distinción de género dual, entendido esto como falta o carencia.

Desde el lugar de la crítica a la modernidad/colonialidad, en cambio, la no existencia de la marca binaria para género es un elemento más que se suma al abanico de negatividades que conlleva la diferencia colonial. Desde la perspectiva de los saberes de algunas de las culturas ancestrales, género -y también patriarcado-son categorías que les son ajenas y que sólo funcionan para ocultar las formas propias y particulares de ser mujer, hombre o ambos, ya que en sus prácticas de interrelación no existen tales clasificaciones y polaridades propias de la cultura blanca, formando parte de lo que Lozano llama "el habitus colonial moderno", ya que esas categorías pueden ser “... parte del arsenal del amo -herramientas de la razón imperial-con las que es imposible destruir su casa” (Walsh, 2016: 170) ${ }^{9}$, que impone así una violencia implícita sobre las subjetividades.

\section{HACIA UN MODO-MUY-OTRO}

Desandado hasta acá - muy parcialmente- el camino de la larga lucha por la construcción del género, surgen nuevos interrogantes acerca de cómo abordar rutas alternativas por las que transitemos todes creativa y proyectivamente hacia andares otros. Estamos acá en un "tercer lugar", en un campo de fuerzas en el que se actualizan las contradicciones, en el que la lucha por la hegemonía se traduce en el diseño de unas lindes simbólicas, lingüísticas, subjetivas, representacionales "otras", altamente diferenciadas del canon en vigencia.

El horizonte está abierto a diversas propuestas disruptivas del statu quo. Por un lado, las experiencias que subvierten ese orden dando lugar a relaciones de intersexualidad -como propone Lugones (2008)- que van más allá de lo biológico para asumir formas de organización social igualitarias y feminocéntricas, afirmando la inexistencia de patriarcado en las sociedades precoloniales. Por otro, con propuestas que oscilan entre reconocer una cierta continuidad del patriarcado preexistente al contacto intercultural (Segato, 2014) y para dar forma a la alternativa del empoderamiento de lo erótico (Ferrera-Balanquet (2015), en convergencia con la potencialidad de lo andrógino como energía creativa y fuerza vital (Walsh, 2016).

La potencialidad de lo andrógino se manifiesta hoy en variadas expresiones culturales, vivido y pensado como una energeia regeneradora de la manifestación de Eros frente a Thanatos, como forma de re-existencia para una humanidad hoy des-centrada. La revulsión de las prácticas y los discursos se extiende cada vez más, vislumbrando la posibilidad de formas de conviviencia que no respondan a las propias de la norma heteronormativa dominante. Ya sea que esos diseños encuentren su fundamento en la persistente memoria comunal de las culturas originarias o afrodescendientes o se sustenten en un feminismo de ruptura retroalimentado en una manera otra de comprender -y asumir- el pensamiento de Occidente construyendo relaciones transmodernas (Dussel, 2006). Es desde esta herencia que una luchadora feminista, buscadora 
consecuente de horizontes-otros, en la subversión que provoca la poesía, moldea la borradura de los sexos en la plenitud de la androgenia, concebida aquí como lo Uno, como el encuentro entre "cuerpos discontinuos":

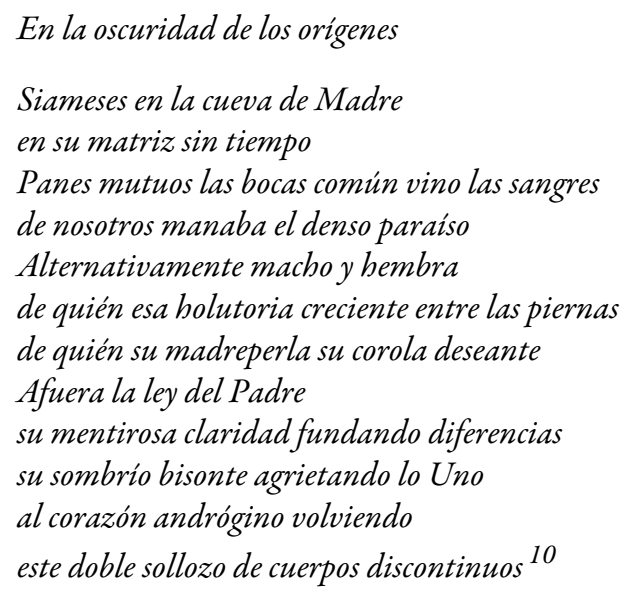

La construcción de estas "nuevas miradas" para generar modos otros de hacer la historia del género, reclama escuchar a quienes quedaron y quedan excluidos de participar armónicamente en la vida social por las prescripciones que instituye la hegemonía heteronormativa. Se asume, así, una posición política y epistemológica que da forma a la construcción de un pensamiento propio emergente de la experiencia concreta en pos de mundos-de-otro-modo.

\section{ReFERENCIAS}

Alegre, L. (2016). "La traducción intercultural como acción y cooperación descolonizante”. En Lockward, Alanna (Comp.) (2016), BE.BOP 2012-2014. El cuerpo en el continente de la conciencia negra. (pp. 191-198). Buenos Aires, Ediciones del Signo. Colección El Desprendimiento.

Alvarado, M. (2017). “Interrupciones en Nuestra América, con voz de mujeres”. En Alvarado Mariana y de Oto, Alejandro (2017), Metodologias en contexto. Intervenciones en teoria feminista /poscolonial/ latinoamericana. (pp. 33-47). Buenos Aires: CLACSO.

de Souza Santos, B. (1998). De la mano de Alicia. Lo socialy lo político en la posmodernidad. Bogotá: Ediciones Uniandes.

Di Prieto, P. (2015). “Andar de costado: racialización, sexualidad y descolonización del mundo travesti”. En Ferrera Ferrera Balanquert, M. (Comp.). Andar erótico decolonial. (pp. 131-151) Buenos Aires: Ediciones del Signo, Colección El Desprendimiento.

Dussel, E. (2006). Filosofía de la cultura y la liberación. México: Universidad Autónoma de México.

Espinosa Miñoso, Y. (2015). "El futuro ya fue. Una crítica a la idea de progreso en las narrativas de liberación sexogenéricas y queer identitarias en Abya-Yala”. En Ferrera Ferrera Balanquert, M (Comp.). Andar erótico decolonial. (pp. 21-38). Buenos Aires: Ediciones del Signo, Colección El Desprendimiento.

Femenías, M.L. (2004). "Lectura excéntrica y cambio de paradigma: des-invisibilización de los a-priori históricos de género". Imprevue, $1 \& 2$, pp. 207-226.

Ferrera Balanquert, M. (Comp.). (2015). Andar erótico decolonial. Buenos Aires: Ediciones del Signo, Colección El Desprendimiento.

Lockward, A (Comp.). (2016), BE.BOP 2012-2014. El cuerpo en el continente de la conciencia negra. Buenos Aires, Ediciones del Signo. Colección El Desprendimiento.

Lugones, M. (2008). “Colonialidad y género: hacia un feminismo descolonial”. En W. Mignolo (Comp.) Género y descolonialidad. Buenos Aires: Duke Universisty/Ediciones del Signo. (13-54).

Palermo, Z. (2009). “Articulación género-raza en procesos de decolonización”, en Lavou Zoungbo y Marlen Marty Imaginaire racial et projections identitaires. Perpignan: Press Universitaires de Perpignan. (97-117). 
Palermo, Z; Quintero, P (Coord.). (2014). Anibal Quijano. Textos de fundación. Buenos Aires: Ediciones del Signo, Colección El Desprendimiento.

Quijano, A. (2001). "Colonialidad del poder, globalización y democracia”, en Tendencias Básicas de Nuestra Era, Caracas: Instituto de Altos Estudios Internacionales. Reproducido en Trayectorias, Revista de CCSS, México: Univ. Autónoma de Nuevo León, México, Año 4, Nos. 7/8, setiembre 2001-2002, pgs. 58-91.

Segato, Rita (2012). "Género y colonialidad: En busca de claves de lectura y de un vocabulario estratégico descolonial.", 2012. En: http://nigs.paginas.ufsc.br/files/2012/09/genero_y_colonialidad_en_busca_de_claves_de_lectura_ y_de_un_vocabulario_estrategico_descolonial_ritasegato.pdf

Segato, R. (2014). "El sexo y la norma: frente estatal, patriarcado, desposesión, colonialidad". Revista Estudos Feministas, 22(2), 593-616, 2014.

Walsh, C. (2016). “Sobre el género y su modo-muy-otro", en Pablo Quintero (Comp.), Alternativas descoloniales al capitalismo colonial/moderno. (pp.165-181). Buenos Aires: Ediciones del Signo, Colección El Desprendimiento, .

\section{Notas}

1 Remito acá sólo a una selección de los escritos de Aníbal Quijano en Palermo y Quintero (Coord.) (2014).

2 “...el fenómeno del poder - reitero este conocido fragmento del sociólogo- se caracteriza como un tipo de relación social constituido por la co-presencia permanente de tres elementos: dominación, explotación y conflicto, que afecta a las cuatro áreas básicas de la existencia social y que es el resultado y la expresión de la disputa por su control: 1) el trabajo, sus recursos y sus productos; 2) el sexo, sus recursos y sus productos; 3 ) la autoridad colectiva (o pública), sus recursos y sus productos; 4) la subjetividad / intersubjetividad, sus recursos y sus productos [...] las relaciones de poder que se constituyen en la disputa por el control de tales áreas [...] no nacen ni se derivan las unas de las otras, pero no pueden existir [...] las unas sin las otras. Forman un complejo estructural cuyo carácter es siempre histórico y específico [...] se trata siempre de un determinado patrón histórico de poder" (2001, pag. 50). [El destacado es mío].

3 En el artículo antes referido, Walsh revisa analíticamente y enriquece los aportes de María Lugones contrastivamente con los de Rita Segato y otras feministas afro y de Abya-Yala. Una interesante historización de la exclusión de la voz de mujer en Nuestra América se lee en Mariana Alvarado (2017).

4 En este orden los movimientos contra la violencia de género, nucleados en Ni Una Menos en la sociedad argentina, generan efectos insospechados en la formación del nuevo imaginario social, operando en distintos sectores; vgr.el movimiento de Actrices Argentinas.

5 Recordemos que el dominio en tiempos de la conquista de estas tierras se ejerció a través de la religión, las armas y el lenguaje, modelando la estructura patriarcal.

6 Basta revisar en los medios electrónicos para constatar la existencia de innumerables organizaciones nacionales e internacionales, de nucleamientos independientes, de investigaciones académicas en una red abierta y heterogénea que, de uno u otro modo, se enfocan en distintos aspectos de la problemática.

7 Cfr. entre otros, Yuderkis Espinoza Miñoso (2015), Di Pietro (2015) y Alegre (2016), publicados en la Colección El Desprendimiento de Ediciones del Signo.

8 Uso del pronombre personal le en función de objeto directo sustituyendo a lo/la.

9 C. Walsh en su recorrido por las distintas posiciones de estas feministas, retoma tal pregunta de la afrocolombiana Betty Ruth Lozano, Op. Cit. pág.179. Ver también Ferrera-Balanquet (2015) y Lockward (2016).

10 Del libro El Corazón Tatuado, de Teresa Leonardi Herrán, Salta, 1990. En la edición del Fondo Editorial (Sec. de Cultura de la Provincia. de Salta), Poesía Reunida, el poema se encuentra incluido en el libro "Memoria de los comulgantes", pag. 106. 